\title{
Nutrition Assessment and Intervention in a Pediatric Patient with Angelman Syndrome: A Case Presentation Highlighting Clinical Challenges and Evidence-Based Solutions
}

\author{
Kelly Fisher ${ }^{\mathrm{a}, \mathrm{b}}$ Jane Keng ${ }^{\mathrm{c}} \quad$ Jane Ziegler ${ }^{\mathrm{a}}$ \\ ${ }^{a}$ Department of Clinical and Preventive Nutrition Sciences, Doctor of Clinical Nutrition Program, School of Health \\ Professions, Rutgers University, Newark, NJ, USA; ${ }^{b}$ Department of Nutritional Sciences, Texas Christian University, \\ Fort Worth, TX, USA; ' Gastroenterology and Nutrition Clinic, Cook Children's Medical Center, Fort Worth, TX, USA
}

\section{Keywords}

Angelman syndrome · Nutrition · Pediatrics · Human genetics $\cdot$ Child nutrition disorders

\begin{abstract}
Background: Angelman syndrome (AS) is a rare disorder of genetic imprinting which results in intellectual and developmental disability. It meets criteria of a disorder of neurologic impairment. A deletion in the long arm of chromosome 15 (del 15q11.2-q13) is responsible for about $70 \%$ of cases of AS (deletion genotype). Summary: There is a paucity of evidence to allow algorithmic nutrition assessment and intervention in pediatric patients with AS. Therefore, our objective is to use a case presentation to provide an example of nutrition assessment and intervention in a pediatric patient with the deletion genotype of AS and then highlight common challenges to providing evidenced-based nutrition care. For the highlighted challenges, we suggest evidencebased solutions to provide a resource for clinicians who may encounter similar challenges in clinical practice. Key Messages: There are genotype-phenotype correlations in AS that can help guide clinicians regarding nutritionally relevant clinical characteristics and corresponding interventions
\end{abstract}

that are patient specific. The deletion genotype in AS is associated with multiple characteristics that are relevant to nutrition care and may also be different and/or more severe than characteristics seen in other AS genetic mechanisms. There is also overlap in certain nutritionally relevant clinical characteristics between AS and other conditions, including Prader-Willi syndrome, autism spectrum disorders, and disorders of neurological impairment like cerebral palsy. Clinicians can utilize nutrition resources related to these conditions to expand the scope of relevant resources available.

(c) 2019 The Author(s)

Published by S. Karger AG, Basel

\section{Introduction}

Angelman syndrome (AS) is a rare disorder of genetic imprinting which results in intellectual and developmental disability [1-4]. It meets criteria of a disorder of neurologic impairment (NI) [5], with common clinical characteristics that include speech impairment/absence, movement disorder, and/or unique behaviors such as frequent or inappropriate laughter, easily excitable personality, and hand flapping; seizures are seen in almost all

\begin{tabular}{ll}
\hline KARGER & $\begin{array}{l}\text { (c) } 2019 \text { The Author(s) } \\
\text { Published by S. Karger AG, Basel }\end{array}$ \\
E-Mail karger@karger.com & $\begin{array}{l}\text { This article is licensed under the Creative Commons Attribution- } \\
\text { NonCommercial-NoDerivatives 4.0 International License (CC BY- } \\
\text { NC-ND) (http://www.karger.com/Services/OpenAccessLicense). } \\
\text { wwwage and distribution for commercial purposes as well as any dis- } \\
\text { tribution of modified material requires written permission. }\end{array}$
\end{tabular}

Kelly Fisher, MS, RD, CSP, LD

Department of Clinical and Preventive Nutrition Sciences

Doctor of Clinical Nutrition Program, School of Health Professions, Rutgers University 65 Bergen St., Suite 157, Newark, NJ 07107 (USA)

E-Mail kpf32@shp.rutgers.edu 
Fig. 1. Drawing of $15 \mathrm{q} 11.2-\mathrm{q} 13$ deletion regions showing $\mathrm{BP}$ regions $\mathrm{BP} 1-\mathrm{BP} 6$. Class I deletions initiate at BP1 and terminate at BP3 ( $\sim 40 \%$ of deletions). Class II deletions initiate at BP2 and terminate at BP3 ( $~ 50 \%$ of deletions). The remaining cases of the deletion genotype span the larger region from $\mathrm{BP} 1$ to $\mathrm{BP} 5$, but rarely more $(\sim 10 \%)$. Genes in circles are biparentally expressed (nonimprinted). The AS and PWS imprinting center (IC) elements are AS-SRO and PWS-SRO, respectively. The SNURF-SNRPN gene has some overlap with PWS-SRO. UBE3A-AS is the SNURF-SNRPN sense/UBE3A antisense transcript [6].

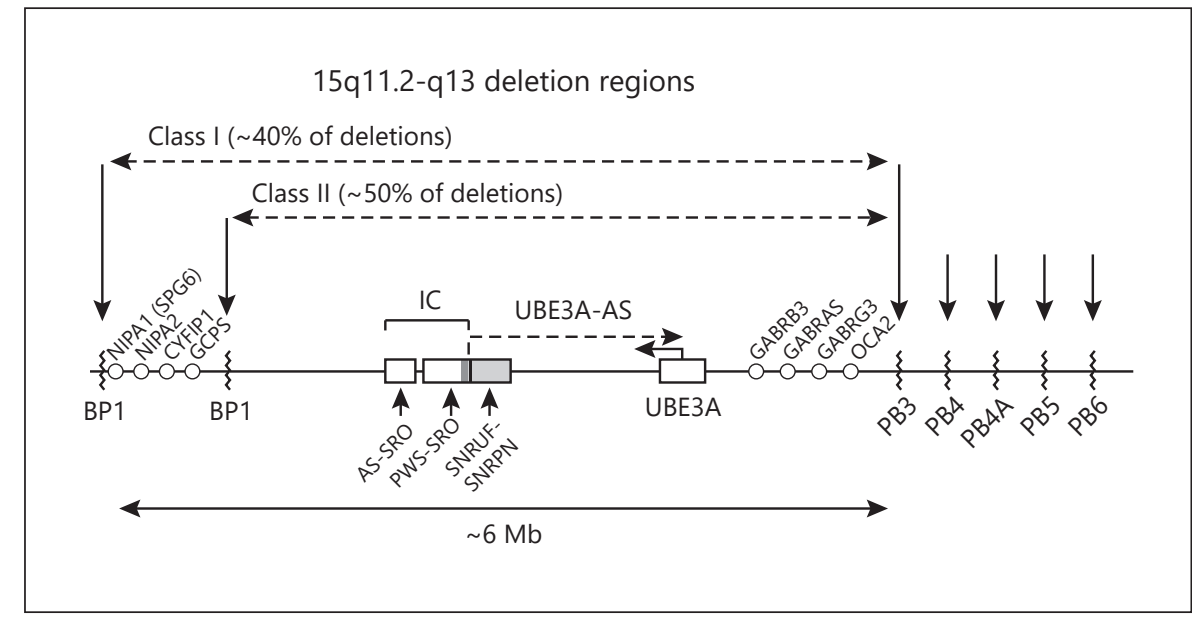

cases $[6,7]$. AS was originally described by Dr. Harry Angelman in 1965 and deemed "happy puppet syndrome" because of the common clinical characteristics that were seen in the initial case presentations [4]. Nutritionally relevant clinical characteristics that may be present in subsets of patients with AS include feeding difficulties, microcephaly after infancy, hyperphagia, food selectivity, constipation, and obesity $[6,7]$.

AS has an estimated prevalence of 1/15,000 [4] and a recent estimated incidence of $1: 22,305$ [8] to 1:24,580 [9] live births. While AS may be encountered infrequently in clinical practice, it is not uncommon for the clinician working in a pediatric specialty area to provide care for children with special health care needs, who represent $18.8 \%$ of children $<18$ years of age in the USA based on data from 2016-2017 [10]. The 2015 position statement of the Academy of Nutrition and Dietetics on nutrition services for individuals with intellectual and developmental disabilities and special health care needs recognizes nutrition services performed by a registered dietitian as a vital component for comprehensive care in this population, which would include AS [11]. AS is not a degenerative disorder and one of the main benefits in early diagnosis is early therapeutic intervention [1]. Interprofessional care is paramount for optimal medical management in AS.

\section{The Genetics and Pathophysiology of AS}

In typical genetics, a chromosome 15 pair exists with 1 maternally derived copy and 1 paternally derived copy $[3,4]$. Each chromosome 15 carries the ubiquitin protein ligase E3A (UBE3A) gene, which is important in the coding of enzymes necessary for protein degradation via the ubiquitin proteasome pathway $[1,12]$. UBE3A is neces- sary for normal brain neuron development and synaptic function $[1,3]$. In the brain, the paternally derived UBE3A gene is silenced and therefore neurons depend on UBE3A from the maternally derived gene $[1,13]$. A unique characteristic of chromosome 15 is that loss of function in the maternally derived gene results in AS, whereas loss of function in paternally derived genes results in PraderWilli syndrome (PWS) $[3,4]$. Figure 1 shows the chromosome 15q11.2-q13 deletion regions, breakpoints (BP), and genes encompassed in the chromosomal region. The parental origin of imprinted genes in the 15q11-q13 region of chromosome 15 affects their expression. The maternal chromosome is highly methylated, but the paternal chromosome is primarily unmethylated [14]. The paternally inherited UBE3A is silenced because the "antisense" transcript UBE3A-ATS is expressed via the unmethylated paternal imprinting control center, but the RNA transcript is not expressed in the methylated maternal imprinting control center (Fig. 1) [12, 13]. Therefore, the loss of maternally derived genes in AS results in different genetic and epigenetic alterations and subsequent losses of expression in different sets of genes versus PWS, and phenotypic differences [14-16]. The pathophysiology of AS involves loss of function or expression in the only active UBE3A gene due to abnormal methylation at $15 \mathrm{q} 11.2-\mathrm{q} 13$ or a pathogenic variant, disrupting typical neurodevelopment $[1,6,13]$.

A deletion in the long arm of chromosome 15 (del $15 \mathrm{q} 11.2-\mathrm{q} 13$ ) is responsible for about $70 \%$ of cases of AS and will be the focus of our case-related discussion $[3,6]$. The majority of the remaining cases of AS result from paternal uniparental disomy (UPD) (where 2 copies of the paternally derived chromosome are inherited), imprinting defect (ID) (where the maternally derived chromo-
Fisher/Keng/Ziegler 
some is "imprinted" with the same coding as the paternally derived chromosome, effectively silencing it as well), or a mutation in the UBE3A gene itself on the maternally derived chromosome $[1,3,4,7]$. Regardless of the underlying genetic mechanism, all cases of AS result in insufficient expression or function of UBE3A. However, the size and location of the deletion in the deletion genotype has implications for haploinsufficiency of various genes adjacent to UBE3A, which helps to explain why a more severe phenotype results $[6,15,17]$. Class I and II deletions (5-7 Mb in size) include the entire imprinted region of $15 \mathrm{q} 11.2-\mathrm{q} 13$ and multiple nonimprinted genes (Fig. 1) $[6,17]$.

The deletion genotype in AS is associated with more severe clinical findings, such as more severe seizures, ataxia, microcephaly, and hypotonia. More patients are also nonambulatory, have lower weights at birth and until at least the age of 5 years, and have gastrointestinal issues and feeding difficulties that may require enteral feeding $[1,7,18-20]$. In contrast, patients with the UPD and ID genotypes of AS have been reported to display hyperphagia and other negative/inappropriate food behaviors which may result in obesity $[7,16,19,21]$. However, while the hyperphagic behaviors are labeled, characterization is minimal, if at all [7, 16, 19, 21]. Buiting et al. [17] detail genotype-phenotype correlations to help explain these findings. First, haploinsufficiencies of nonimprinted genes in the deletion genotype have been implicated in some of the resultant clinical manifestations, such as haploinsufficiencies in certain GABA receptor genes explaining the increased seizure risk in these patients [17]. Second, other genes that are important for language and behavior are encompassed within the 15q11.2-q13 area, and these would also be lost in the deletion genotype of AS [17]. With regard to food selectivity and hyperphagia in AS, Salminen et al. [16] propose that an increased dosage of paternally expressed genes in the UPD and ID AS genotypes may explain why increased food selectivity, hyperphagic behaviors, and higher BMI levels are seen. The authors propose a model suggesting that an increased dosage of the MAGEL2 gene (paternally expressed) may contribute to elevated dopamine levels, thereby increasing the hedonic value of food through dopamine reward pathways, which may in turn explain both food selectivity and the development of hyperphagia at an early age [16]. MAGEL2 is found between BP2 and the imprinting center in the region of 15q11.2-q13 of chromosome 15, and it is expressed in the hypothalamus [16].

There is a paucity of evidence to allow algorithmic nutrition assessment and intervention in pediatric patients with AS. Therefore, our objective is to use a case presentation to provide an example of nutrition assessment and intervention in a pediatric patient with AS and then highlight common challenges to providing evidence-based nutrition care. For the highlighted challenges, we suggest evidence-based solutions to provide a resource for clinicians who may encounter similar challenges in their clinical practice.

\section{Case Presentation}

A Hispanic female (aged 11 years and 6 months) presented with complaints of weight loss at her gastroenterology follow-up to discuss possible gastrostomy button placement. She was born full term and was diagnosed with the deletion genotype of AS at about 10 months of age. Her medical history included seizures, global developmental delay, hypotonia, and swallow dysfunction. On initial presentation, she was nonambulatory and in a wheelchair, she was nonverbal, and she had a nasogastric tube in place. She displayed additional behaviors typical of AS, including unusual jerky arm movements and an easily excitable personality, and she had characteristic sleep disturbances $[1,4,7]$. Her behavior was somewhat hyperactive and she seemed agitated. The patient had been received nutrition, speech, occupational, and/or physical therapy at various times since her AS diagnosis. Table 1 provides a summary of patient anthropometrics during the case timeline.

\section{Food/Nutrition-Related History}

She had a history of previous weight loss and had been on a high-calorie diet including oral nutritional supplements with fiber since the age of 10 years. She also had a history of 2 abnormal video function swallow studies (VFSS). The first VFSS at age 5 years showed aspiration of thin liquids and the patient was prescribed nectar-thick liquids, smooth purees, and mechanical soft solids. Then, at 11 years 2 months of age, the patient had a major seizure episode that required hospitalization, and subsequently developed increased coughing with oral feedings. A repeat VFSS revealed a declined swallow function with severe oral and pharyngeal phase dysphagia and frequent silent aspirations with all consistencies of liquids (thin, half nectar, nectar, and honey). The speech language pathologist was unable to determine safety of purees or solids, and an NG tube was placed. Prior to NG tube placement, her family reported she had a robust appetite and intake of a 1 calorie per milliliter $(\mathrm{kcal} / \mathrm{mL})$ nutritional supplement drink with fiber by mouth 3 times daily.

\section{Treatment Course}

The patient was admitted for gastrostomy button placement and repeat VFSS to assess the safety of solid foods. She was found to have pharyngeal dysphagia characterized by aspiration of thin and thick purees, significant residue with soft solids (one bite required 9 additional swallows to clear), and oral dysphagia characterized by overall weakness with vertical munch observed to breakdown the bite. A "munch" is an abnormal chewing pattern for an older patient. It refers to up and down jaw movement while chewing, versus an age-appropriate rotary chewing pattern with circular jaw movements that facilitate adequate grinding of food. The 
Table 1. Summary of patient anthropometrics during the case timeline

\begin{tabular}{|c|c|c|c|c|}
\hline Anthropometrics ${ }^{\mathrm{a}}$ & Previous visit & Outpatient visit 1 & Hospital discharge & Outpatient visit 2 \\
\hline Weight (percentile), kg & $22.4(<5$ th $)$ & 21.7 (<5th) & $22.3(<5$ th $)$ & $24.3(<5$ th $)$ \\
\hline Weight-for-age z-score & -3.37 & -3.83 & -2.69 & -3.04 \\
\hline Height-for-age z-score & N/A & -3.48 & -2.83 & -2.90 \\
\hline Tibial length (est. stature), $\mathrm{cm}$ & N/A & N/A & N/A & $\begin{array}{c}28.4(123.4 \mathrm{~cm} \rightarrow \\
<5 \% ; \mathrm{z} \text {-score }-3.37)\end{array}$ \\
\hline IBW, $\mathrm{kg}(\%)$ & N/A & $26.5(82)$ & $21.8(88)$ & $28.9(84)$ \\
\hline Growth velocity & $+1.6 \mathrm{~kg}(\sim 7 \%$ gain $\times 119$ days $)$ & $-0.7 \mathrm{~kg}(\sim 3 \%$ loss $\times 77$ days $)$ & $+0.6 \mathrm{~kg}(\sim 3 \%$ gain $\times 3$ days $)$ & $+2 \mathrm{~kg}(\sim 9 \%$ gain $\times 39$ days $)$ \\
\hline MUAC (percentile; $z$-score), cm & N/A & N/A & N/A & $19.5(5$ th; -1.68$)$ \\
\hline
\end{tabular}

a Based on CDC growth charts for children aged 2-20 years (https://www.cdc.gov/growthcharts/clinical_charts.htm). est., estimated; N/A, not available.

speech language pathologist recommended nothing by mouth. She was seen by the hospital dietitian and was changed to a highercalorie formula to address the weight loss while honoring the family's request to continue only 3 feedings daily. She was discharged on postoperative day 2 with a demonstrated tolerance of her new gastrostomy button feeding regimen. The patient was seen again at her 1 month postoperation GI follow-up with continued tolerance of her gastrostomy button feeding regimen. She was visibly calmer and had gained weight (Table 1 ). Her parents reported subjective increases in strength, with more energy for mobility to "roll around" and play, and an improved demeanor at home. She exhibited an improving nutritional status with tolerance of her current gastrostomy button feeding regimen.

\section{Discussion/Conclusion}

To our knowledge this is the first case documentation involving nutrition assessment and intervention in a pediatric patient with AS. Clinicians working with children with AS need to remember that a variety of disciplines are likely involved in the care of each patient. There are multiple studies showing that parental/caregiver stress is high in those caring for children with AS [20, 22-24]. Parents/ caregivers of children with AS likely have to schedule and balance appointments with any or all of the following: a pediatrician, a neurologist, a gastroenterologist, a speechlanguage pathologist, an occupational therapist, a physical therapist, a nutritionist, and/or an orthopedist. Abnormal sleep patterns, including frequent night-time waking and fewer hours asleep, also impact the sleep of parents caring for children with AS $[22,23]$. Individuals with AS may only get 5-6 hours of broken sleep per night, but they may not exhibit signs of drowsiness during the day, suggesting that overall sleep needs may be lower compared to those of the same age without AS $[16,20]$. Sleep disturbances are frequently noted as a parental/caregiver stressor in caring for children with AS, along with behavioral issues [22, 23]. Food selectivity and "picky" eating, often similar to those seen in children with autism spectrum disorders, are foodrelated behaviors which clinicians may encounter when working with patients with AS $[16,19,25]$. The lifespan in patients with AS is not reduced and therefore patients will require lifelong parental/caregiver supervision and assistance to accomplish activities of daily living [20]. It is the responsibility of the registered dietitian working with patients with AS to tailor the medical nutrition therapy to fit the individual needs of each patient, including input from family and caregivers to ensure that the feeding plan fits their goals and needs as well $[11,26]$. The following discussion will focus on aspects of nutrition assessment and intervention specific to our patient with a somewhat severe and less common clinical characteristics associated with the deletion phenotype [18]. Table 2 provides a concise resource to guide clinicians to the common nutritionrelated clinical characteristics for all of the AS genotypes and includes areas of consideration for nutrition assessment and intervention. There is overlap in certain nutritionally relevant clinical characteristics between AS and other conditions, including PWS, autism spectrum disorders, and disorders of NI like cerebral palsy, which expands the scope of relevant resources available to clinicians.

\section{Nutrition Assessment}

The European Society for Pediatric Gastroenterology, Hepatology and Nutrition (ESPGHAN) published a clinical guideline in 2017 for the evaluation and treatment of gastrointestinal and nutritional complication in children with neurological impairment [5]. This consensus docu-
Fisher/Keng/Ziegler 
Table 2: Nutrition-related genotype-phenotype correlations in patients with AS to guide nutrition assessment and intervention

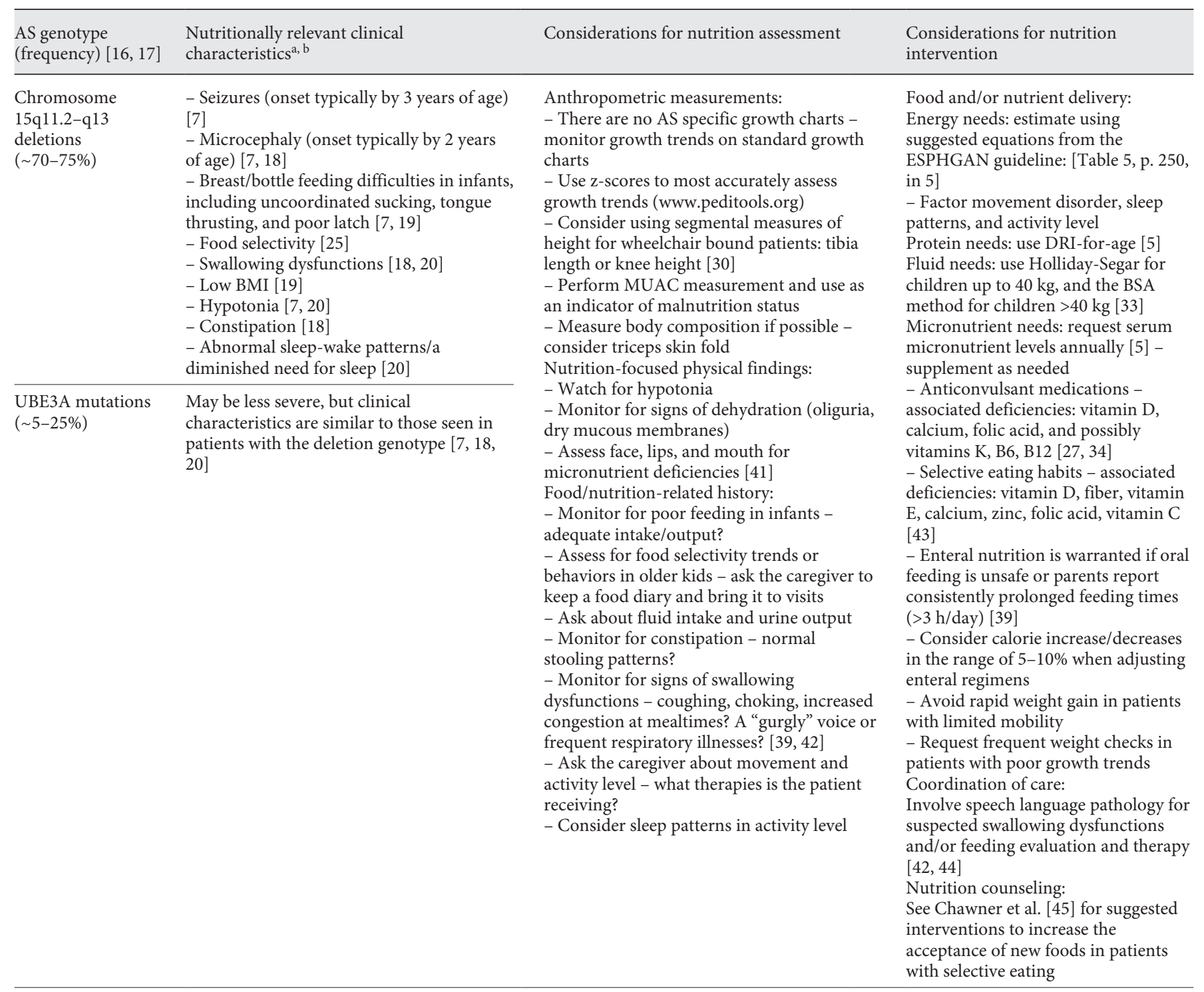

(Table continued on next page.)

ment serves as a valuable resource for clinicians working with pediatric patients with AS with a severe deletion phenotype. The ESPGHAN consensus guideline recommends that assessment of the nutritional status of children with NI should not be based solely on weight and height measurements and should include measurement of fat mass by skinfold thickness [5]. There are no specialty growth charts available for children with AS and therefore all anthropometrics should be tracked on the standard World Health Organization (WHO) growth charts for children aged 0-24 months or the Centers for Disease Control and Prevention (CDC) growth charts for children above 24 months [5].

Nutrition Assessment and Intervention in a Pediatric Patient with AS
Our case presentation highlights the common challenge of inconsistencies and probable inaccuracies in measurements of stature in nonambulatory children with NI. The stature records of the patient from our case (Table 1) demonstrate a relatively common presentation regarding trends. She had no recorded stature from her previous visit, and then presented a large recorded increase from outpatient visit 1 to hospital discharge 3 days later. The height from hospital discharge was re-recorded for outpatient visit 2 and it was not verified. Contractures, impaired tone, scoliosis, and/or nonambulatory status all increase the difficulty in obtaining accurate measurements of stature in children with NI $[5,27]$. Recumbent 
Table 2 (continued)

\begin{tabular}{|c|c|c|c|}
\hline $\begin{array}{l}\text { AS genotype } \\
\text { (frequency) }[16,17]\end{array}$ & $\begin{array}{l}\text { Nutritionally relevant clinical } \\
\text { characteristics }^{\text {a, b }}\end{array}$ & Considerations for nutrition assessment & $\begin{array}{l}\text { Considerations for nutrition } \\
\text { intervention }\end{array}$ \\
\hline UPD ( 1-2\%) & $\begin{array}{l}\text { - Increased birth weight }[19,40] \\
\text { - Poor feeding in infants }[18] \\
\text { - Normal to large head circumference [40] } \\
\text { - Rapid BMI increase between } 2 \text { and } 5 \text { years } \\
\text { of age [19] } \\
\text { - Obesity in older children [19] } \\
\text { - Hyperphagic behaviors [19] } \\
\text { - Constipation [18] } \\
\text { - Abnormal sleep-wake patterns/ } \\
\text { a diminished need for sleep [20] }\end{array}$ & \multirow{2}{*}{$\begin{array}{l}\text { Anthropometric measurements: } \\
\text { - Growth patterns are more typical - plot on } \\
\text { standard growth charts } \\
\text { - Use z-scores to most accurately assess } \\
\text { growth trends for weight and length } \\
\text { (www.peditools.org) } \\
\text { - Monitor closely for increasing BMI } \\
\text { between } 2 \text { and } 5 \text { years of age } \\
\text { Food/nutrition-related history: } \\
\text { - Monitor for poor feeding in infants - } \\
\text { adequate intake/output? } \\
\text { - Monitor for constipation - normal } \\
\text { stooling patterns? } \\
\text { - Assess for hyperphagia and other } \\
\text { abnormal food behaviors, such as stealing/ } \\
\text { storing food, pica-like consumption, and/or } \\
\text { preoccupation with food [18, 25] } \\
\text { - Composition and timing of meals/snacks? } \\
\text { - Child's access level to food at home and } \\
\text { away from home? } \\
\text { - Food used as reward? } \\
\text { - Evidence of food seeking behavior: stealing } \\
\text { food, nighttime eating, eating food left by } \\
\text { others? [46] }\end{array}$} & \multirow{2}{*}{$\begin{array}{l}\text { Food and/or nutrient delivery: } \\
\text { Energy needs: estimate using } \\
\text { suggested equations from the } \\
\text { ESPHGAN guideline [5] } \\
\text { - Factor movement disorder, sleep } \\
\text { patterns, and activity level } \\
\text { - Calorie restriction may be needed to } \\
\text { prevent or address obesity } \\
\text { Protein needs: use DRI-for-age [5]; } \\
\text { use with adjusted body weight in } \\
\text { patients with obesity ( } 15-20 \% \\
\text { calories as protein) [33] } \\
\text { Fluid needs: use Holliday-Segar for } \\
\text { children up to } 40 \text { kg and the BSA } \\
\text { method for children }>40 \text { kg; use with } \\
\text { adjusted body weight in patients with } \\
\text { obesity, or } 1 \text { mL/calorie [33] } \\
\text { - Regular weight checks may be } \\
\text { needed in patients with hyperphagia } \\
\text { [47] } \\
\text { Nutrition education: } \\
\text { - See the Endocrine Society clinical } \\
\text { practice guideline on assessment, } \\
\text { treatment, and prevention [46] } \\
\text { - Controlled access to food may be } \\
\text { needed for patients with hyperphagia } \\
\text { [47] } \\
\text { - A structured schedule and plan for } \\
\text { meals and snacks can provide } \\
\text { psychological food security and may } \\
\text { be helpful for patients with } \\
\text { hyperphagia [ } 47 \text { ] } \\
\text { Nutrition counseling: } \\
\text { See the position paper from the } \\
\text { Academy of Nutrition and Dietetics } \\
\text { for interventions for the prevention } \\
\text { and treatment of pediatric overweight } \\
\text { and obesity [ } 48 \text { ] }\end{array}$} \\
\hline $\begin{array}{l}\text { Imprinting defects } \\
(\sim 1-3 \%)\end{array}$ & $\begin{array}{l}\text { Clinical characteristics are similar to those } \\
\text { seen in patients with the UPD genotype } \\
{[18-20,40]}\end{array}$ & & \\
\hline
\end{tabular}

${ }^{a}$ Common clinical characteristics by AS genotype are listed, but clinicians should not view this list as exclusive. Each patient with AS is unique and may display clinical characteristics uncommon to their genotype. ${ }^{b}$ Clinical features found in $100 \%$ of patients with AS include: developmental delay, movement/balance disorder, unique behaviors, speech impairment [7].

length can be measured even in older children when they cannot stand, but this requires the child to be lifted out of their wheelchair and placed on the examination table, and it requires the child to lie straight and still for an accurate measurement. In clinical practice, this is unlikely to occur at every visit or even frequently. It is more common that the stature reported by the parent is recorded in the patient's medical record. Segmental measures, such as tibia length or knee height, are an alternative method to estimate stature in this population, but they require special equipment and should be performed by a trained clinician $[5,28-30]$. Tibia length has been shown to correlate strongly with prone measurement of stature in children with moderate-to-severe cerebral palsy and only requires a tape measure to perform [28]. Our case presentation supports the use of tibia length measurement as an easily obtained proxy method to estimate height in nonambulatory children with AS. The derived equations to estimate stature using segmental measures like tibia length include an inherent degree of error and they should not be used in BMI calculations [30]. Instead, they can be used to verify suspected inaccurate measurements of stature and more accurately track linear growth over time [5].

The current consensus guideline from the Academy of Nutrition and Dietetics and the American Society for Enteral and Parenteral Nutrition on the assessment and documentation of malnutrition (undernutrition) recommends use of weight-for-height, BMI-for-age, and/
48
Fisher/Keng/Ziegler 
or mid-upper arm circumference (MUAC) z-scores as single data points to support the diagnosis of mild, moderate, or severe malnutrition [31]. We use the Peditools website (www.peditools.org) to obtain the most accurate $\mathrm{z}$-scores in assessing and documenting the anthropometric measures of our patients. MUAC provides a relatively stable measure of soft tissue growth, but it does not delineate well between fat and muscle tissue $[31,32]$. In this case study, we were not able to measure MUAC at our patient's first visit due to a lack of cooperation, so we based our malnutrition assessment on her BMI-forage $\mathrm{z}$-score. This is not ideal because her BMI was calculated with a height that we suspected to be inaccurate. The MUAC measurement at her second visit post-gastrostomy button and nutrition intervention correlated well with our current assessment of malnutrition based on her BMI for age. MUAC measurement is relatively simple and efficient to perform and it is an indicator of nutritional status that does not rely on an accurate height.

\section{Nutrition Intervention}

To the best of our knowledge, there are no available studies that demonstrate energy needs or expenditure in patients with AS to help guide the design of nutrition interventions [5]. ESPGHAN recommends the use of body weight and fat mass to help estimate energy requirements, but the challenges related to measurement of body composition in children with NI, as noted above, make it unlikely that these measures will be available [5]. Dietary reference intake (DRI)-based equations are reported to overestimate energy needs in patients with NI [5]. However, DRI-based equations represented a gross underestimation of calorie needs in our patient with AS based on her weight loss despite an intake approximately 57\% higher than the DRI for her age ( $66 \mathrm{kcal} / \mathrm{kg})$ [33]. Her NG feeding regimen was consistently reported and verified independently by 2 registered dietitians, validating that her weight loss occurred despite the high energy intake. Although our patient presented in a wheelchair with motor dysfunction, it is probable that her energy needs are higher than might be expected in children with a similar presentation because of her involvement in multiple therapies (physical therapy and occupational therapy), her increased wakeful hours related to characteristic AS sleep disturbances, and her movement patterns that were noted to be somewhat hyperactive and are also characteristic of AS [7]. The patient demonstrated weight gain after alterations were made to her enteral feeding regimen in the hospital after gastrostomy button placement.

Nutrition Assessment and Intervention in a Pediatric Patient with AS
ESPGHAN recommends use of the DRI for protein to estimate needs in children with NI [5]. There is no indication that children with AS have increased protein needs under typical circumstances. It is our clinical experience that the protein needs of patients on reasonable volumes of enteral nutrition are easily met with formulas available on the market. This was true in the case of our patient with AS. Clinicians should be aware of potentially inadequate protein provision when patients are on extremely low volumes of enteral formula. Low-calorie, modular protein products available on the market can be used in these cases to increase the protein provision without significant volume or calorie increases.

ESPGHAN recommends that "careful attention should be paid to hydration status, as children with NI are at risk of dehydration for a variety of reasons (e.g., inability to communicate thirst, drooling, unsafe swallow)" [5]. We found this to be true in our patient who demonstrated fluid needs above the estimation based on the body surface area (BSA) method. Our patient had resolution of dry, cracked lips and subjective strong smelling urine after nutrition intervention which increased fluid provision. Severe speech impairment is found in $100 \%$ of patients with AS, with most patients being nonverbal [7]. Parents of children with AS, and other NI, should be aware of the signs and symptoms of dehydration, including oliguria and dry mucous membranes, because the patient will be unable to communicate thirst [34]. The clinician should perform a nutrition-focused physical examination of the face, lips, mouth, and tongue to assess for micronutrient deficiencies as well as for hydration status [32]. The clinician should always include questions about urine output and description when they interview the patient's family.

Adequate micronutrient provision is another area that is challenging in patients with NI regardless of oral or enteral feeding. Food selectivity and "picky eating" behaviors in orally fed patients increase the risk of micronutrient deficiencies. Our patient's initial enteral intake was slightly below the volume required to meet or exceed $100 \%$ of the DRI for 25 essential vitamins and minerals for children 9-13 years of age according to the formula manufacturer, but the patient had no laboratory evidence of electrolyte or nutrient deficiency. In the case that laboratory abnormalities are encountered in clinical practice, flushes of an oral rehydration solution or skim milk in place of some water are an option to address electrolyte or phosphorus insufficiencies, respectively, without substantial added calories. ESPGHAN recommends that serum micronutrient levels be checked at least annually and 
the use of the DRI for micronutrients to estimate the appropriate micronutrients intake in patients with NI [5]. Specific to AS, Bird [35] conducted a 1-year nonrandomized open-label prospective clinical trial to assess the efficacy of a "methylation regimen" of dietary supplements (L-5-methyltetrahydrofolate, creatine, betaine, and vita$\min B_{12}$ ) to improve measures of developmental function, biochemical parameters, and global DNA methylation. After 1 year of supplementation, there were no significant improvements in any study outcomes in the 65 patients completing the trial, and the authors concluded that "it may not be possible to alter DNA methylation in humans through dietary supplementation" [35]. Seizures are present in at least $80 \%$ of patients with AS and they are also common in the NI population in general, and the ketogenic diet is one treatment option for reducing seizures $[7,34]$. An active clinical trial is seeking to assess the safety and tolerability of fat-based nutritional formulation containing exogenous ketones designed to induce ketosis in children with AS consuming high- and low-carbohydrate diets (NCT03644693). The commonly prescribed anticonvulsant medications are associated with deficiencies of vitamin $\mathrm{D}$, calcium, folic acid, and possibly vitamins $\mathrm{K}, \mathrm{B}_{6}$, and $\mathrm{B}_{12}[27,34]$. Clinicians should monitor for deficiencies in these vitamins and minerals in particular in patients with seizures. Both seizure medications and non-weight-bearing status can have a negative impact on bone status $[5,11,27,34]$.

It is known that even a mild feeding dysfunction can negatively impact the nutrition status and linear growth of patients with NI, and therefore appropriate nutrition prescription in both oral and enteral fed patients is paramount $[36,37]$. However, to the best of our knowledge, there are no studies that provide guidance for specific energy increases to promote weight gain, or energy decreases to prevent weight gain, in patients with AS. Our patient with AS demonstrated higher-than-anticipated energy needs at her first visit. She had a rapid weight gain with a caloric increase $\sim 25 \%$ higher than her previous intake. Access to body composition testing, such as triceps skin fold or dual energy X-ray absorptiometry, would have better characterized the make-up of weight gain, which ideally would include some muscle and not solely added fat. Based on our clinical experience with children with $\mathrm{NI}$, we more routinely intervene with calorie increases or decreases in the range of 5-10\% with a follow-up weight check in 2-4 weeks to assess the adequacy of the change. Our experience is that even a $5 \%$ increase in calories in some physically restricted children with NI can result in a rapid weight gain, most of which is presumed to be fat mass. Ohata et al. [38] demonstrated that weight gain in 26 orally fed pediatric patients with cerebral palsy was more reflective of gains in fat versus muscle tissue, based on ultrasound images of muscle thickness of the quadriceps femoris and fat thickness of the anterior thigh. When adjusting the nutrition prescription of nonambulatory patients with AS, or those with limited mobility, registered dietitians must be cognizant of the impact of rapid weight gain on the ability of parents/caregivers to physically provide care for their children [27]. Frequent "weight checks" should be performed when altering the feeding regimens of patients with NI.

In conclusion, we presented aspects of nutrition assessment and intervention specific to a patient with the deletion genotype of AS with somewhat severe nutritionrelated clinical characteristics, which are relatively uncommon [18]. However, there are nutrition-related genotype-phenotype correlations in AS which can help guide clinicians regarding the more common nutritionally relevant clinical characteristics, and corresponding patientspecific nutrition interventions (Table 2). Feeding should be monitored closely in children with AS throughout infancy and childhood since feeding difficulties are common. Weight status should be monitored closely for both underweight and overweight, noting trends common by AS genotype. Micronutrient intake should be assessed and monitored closely in patients with selective eating or low volumes of enteral intake. Food diaries are one way to monitor the nutrient intake in patients with AS who are orally fed. Hydration status should be monitored in all patients, but particular care should be taken in patients with AS because almost all are nonverbal and may be unable to adequately express thirst. Swallow dysfunction is also found in patients with AS and enteral feeding may be warranted if oral feeding is unsafe or parents report consistently prolonged feeding times ( $>3 \mathrm{~h} /$ day) [39].

\section{Acknowledgement}

The authors wish to thank Dr. Kate Willcutts, DCN, RD, LD, CNSC, for her thorough review and editing.

\section{Statement of Ethics}

The authors have no ethical conflicts to disclose. Institutional Review Board approval was not required by the medical institution where this patient was treated because our single-patient case report and narrative review does not include protected health information. Single-patient case reports are not deemed as research by the medical institution.
Fisher/Keng/Ziegler 


\section{Disclosure Statement}

The authors have no conflict of interests to declare.

\section{Funding Sources}

There were no funding sources for this paper.

\section{Author Contributions}

All of the authors contributed to the conception and design of this work, gave final approval of the version to be published, and agree to be accountable for all aspects of this work in ensuring that questions related to the accuracy or integrity of any part of this work are appropriately investigated and resolved. K.F. drafted this work, and J.K. and J.Z. critically revised it for important intellectual content.

\section{References}

1 Bonello D, Camilleri F, Calleja-Agius J. Angelman Syndrome: identification and Management. Neonatal Netw. 2017 May;36(3): $142-51$.

2 Butler MG. Prader-Willi and Angelman Syndromes: Examples of Genomic Imprinting. 1st ed. New York: McGraw-Hill; 2014. In: Clinical Genomics: Practical Applications in Adult Patient Care [cited May 4, 2018]. Available from: http://accessmedicine.mhmedical. com.proxy.libraries.rutgers.edu/content.aspx ?bookid $=1094 \&$ sectionid $=61907701$.

3 Cheesman KL, Kuzins R. Prader-Willi and Angelman syndromes. Salem Press Encyclopedia of Health. Salem Press; 2014.

4 Williams CA, Peters SU, Calculator SN. Facts About Angelman Syndrome; 2009 [cited June 13, 2018]. Available from: https://www.angelman.org/wp-content/uploads/2015/11/facts_ about as 2009 3-19-10.pdf.

5 Romano C, van Wynckel M, Hulst J, Broekaert I, Bronsky J, Dall'Oglio L, et al. European Society for Paediatric Gastroenterology, Hepatology and Nutrition Guidelines for the Evaluation and Treatment of Gastrointestinal and Nutritional Complications in Children With Neurological Impairment. J Pediatr Gastroenterol Nutr. 2017 Aug;65(2):242-64.

6 Dagli AI, Mueller J, Williams CA. Angelman Syndrome. Seattle, WA: University of Washington; 1998 [updated December 21, 2017; cited August 26, 2019]. Available from: www. ncbi.nlm.nih.gov/books/.

7 Williams CA, Beaudet AL, Clayton-Smith J, Knoll JH, Kyllerman M, Laan LA, et al. Angelman syndrome 2005: updated consensus for diagnostic criteria. Am J Med Genet A. 2006 Mar;140(5):413-8.

8 Luk HM, Lo IF. Angelman syndrome in Hong Kong Chinese: A 20 years' experience. Eur $\mathrm{J}$ Med Genet. 2016 Jun;59(6-7):315-9.

9 Mertz LG, Christensen R, Vogel I, Hertz JM, Nielsen KB, Grønskov K, et al. Angelman syndrome in Denmark. birth incidence, genetic findings, and age at diagnosis. Am J Med Genet A. 2013 Sep;161A(9):2197-203.

10 Maternal and Child Health Bureau. National Survey of Children's Health Fact Sheet; 2018 [cited October 2018]. Available from: https:// mchb.hrsa.gov/sites/default/files/mchb/ Data/NSCH/NSCH-factsheet-2017-release. pdf.
11 Ptomey LT, Wittenbrook W. Position of the Academy of Nutrition and Dietetics: nutrition services for individuals with intellectual and developmental disabilities and special health care needs. J Acad Nutr Diet. 2015 Apr; 115(4):593-608.

12 Khatri N, Man HY. The Autism and Angelman Syndrome Protein Ube3A/E6AP: The Gene, E3 Ligase Ubiquitination Targets and Neurobiological Functions. Front Mol Neurosci. 2019 Apr; 12:109.

13 Tan WH, Bird LM. Angelman syndrome: current and emerging therapies in 2016. Am J Med Genet C Semin Med Genet. 2016 Dec; 172(4):384-401.

14 Bird LM. Angelman syndrome: review of clinical and molecular aspects. Appl Clin Genet. 2014 May; 7:93-104.

15 Margolis SS, Sell GL, Zbinden MA, Bird LM. Angelman Syndrome. Neurotherapeutics. 2015 Jul;12(3):641-50.

16 Salminen II, Crespi BJ, Mokkonen M. Baby food and bedtime: evidence for opposite phenotypes from different genetic and epigenetic alterations in Prader-Willi and Angelman syndromes. SAGE Open Med. 2019 Jan;7: 2050312118823585.

17 Buiting K, Williams C, Horsthemke B. Angelman syndrome - insights into a rare neurogenetic disorder. Nat Rev Neurol. 2016 Oct; 12(10):584-93.

18 Glassman LW, Grocott OR, Kunz PA, Larson AM, Zella G, Ganguli K, et al. Prevalence of gastrointestinal symptoms in Angelman syndrome. Am J Med Genet A. 2017 Oct;173(10): 2703-9.

19 Mertz LG, Christensen R, Vogel I, Hertz JM, Østergaard JR. Eating behavior, prenatal and postnatal growth in Angelman syndrome. Res Dev Disabil. 2014 Nov;35(11):2681-90.

20 Wheeler AC, Sacco P, Cabo R. Unmet clinical needs and burden in Angelman syndrome: a review of the literature. Orphanet J Rare Dis. 2017 Oct;12(1): 164.

21 Welham A, Lau J, Moss J, Cullen J, Higgs S, Warren G, et al. Are Angelman and PraderWilli syndromes more similar than we thought? Food-related behavior problems in Angelman, Cornelia de Lange, fragile X, Prader-Willi and 1p36 deletion syndromes. Am J Med Genet A. 2015 Mar;167A(3):572-8.
22 Goldman SE, Bichell TJ, Surdyka K, Malow BA. Sleep in children and adolescents with Angelman syndrome: association with parent sleep and stress. J Intellect Disabil Res. 2012 Jun;56(6):600-8.

23 Miodrag N, Peters S. Parent stress across molecular subtypes of children with Angelman syndrome. J Intellect Disabil Res. 2015 Sep; 59(9):816-26.

24 Wulffaert J, Scholte EM, Van BerckelaerOnnes IA. Maternal parenting stress in families with a child with Angelman syndrome or Prader-Willi syndrome. J Intellect Dev Disabil. 2010 Sep;35(3):165-74.

25 Barry RJ, Leitner RP, Clarke AR, Einfeld SL. Behavioral aspects of Angelman syndrome: a case control study. Am J Med Genet A. 2005 Jan;132A(1):8-12.

26 Kleinert JO. Pediatric Feeding Disorders and Severe Developmental Disabilities. Semin Speech Lang. 2017 Apr;38(2):116-25.

27 Behavioral Health Nutrition Dietetic Practice Group, Pediatric Nutrition Practice Group. Pocket Guide to Children with Special Health Care and Nutritional Needs. Chicago (IL): Academy of Nutrition and Dietetics; 2012.

28 Kihara K, Kawasaki Y, Yagi M, Takada S. Relationship between stature and tibial length for children with moderate-to-severe cerebral palsy. Brain Dev. 2015 Oct;37(9):853-7.

29 Samson-Fang L, Bell KL. Assessment of growth and nutrition in children with cerebral palsy. Eur J Clin Nutr. 2013 Dec;67(Suppl 2):S5-8.

30 Stevenson RD. Use of segmental measures to estimate stature in children with cerebral palsy. Arch Pediatr Adolesc Med. 1995 Jun; 149(6):658-62.

31 Becker P, Carney LN, Corkins MR, Monczka J, Smith E, Smith SE, et al.; Academy of Nutrition and Dietetics; American Society for Parenteral and Enteral Nutrition. Consensus statement of the Academy of Nutrition and Dietetics/American Society for Parenteral and Enteral Nutrition: indicators recommended for the identification and documentation of pediatric malnutrition (undernutrition). Nutr Clin Pract. 2015 Feb;30(1):14761.

32 Green Corkins K. Nutrition-focused physical examination in pediatric patients. Nutr Clin Pract. 2015 Apr;30(2):203-9. 
33 Buntling KD, Ramsey E, Rich S, Trout S. Growth and Nutrition Assessment Guidelines Pediatric Nutrition Reference Guide. 10th ed. Houston (TX): Texas Children's Hospital; 2013. pp. 6-29.

34 Washington State Department of Health. Nutrition Interventions for Children with Special Health Care Needs. Olympia, WA: Washington State Department of Health; 2010. Available from: https://www.doh.wa.gov/ Portals/1/Documents/8100/961158-CSHCN-NI-en-L.pdf.

35 Bird LM, Tan WH, Bacino CA, Peters SU, Skinner SA, Anselm I, et al. A therapeutic trial of pro-methylation dietary supplements in Angelman syndrome. Am J Med Genet A. 2011 Dec;155A(12):2956-63.

36 Dahlseng $\mathrm{MO}$, Finbråten $\mathrm{AK}$, Júlíusson $\mathrm{PB}$, Skranes J, Andersen G, Vik T. Feeding problems, growth and nutritional status in children with cerebral palsy. Acta Paediatr. 2012 Jan;101(1):92-8.

37 Fung EB, Samson-Fang L, Stallings VA, Conaway M, Liptak G, Henderson RC, et al. Feeding dysfunction is associated with poor growth and health status in children with cerebral palsy. J Am Diet Assoc. 2002 Mar; 102(3):361-73.
38 Ohata K, Tsuboyama T, Haruta T, Ichihashi $\mathrm{N}$, Nakamura T. Longitudinal change in muscle and fat thickness in children and adolescents with cerebral palsy. Dev Med Child Neurol. 2009 Dec;51(12):943-8.

39 Andrew MJ, Parr JR, Sullivan PB. Feeding difficulties in children with cerebral palsy. Arch Dis Child Educ Pract Ed. 2012 Dec;97(6): 222-9.

40 Brennan ML, Adam MP, Seaver LH, Myers A, Schelley S, Zadeh $\mathrm{N}$, et al. Increased body mass in infancy and early toddlerhood in Angelman syndrome patients with uniparental disomy and imprinting center defects. Am J Med Genet A. 2015 Jan;167A(1):142-6.

41 Pediatric NF. Academy of Nutrition and Dietetics; 2015

42 Arvedson JC. Feeding children with cerebral palsy and swallowing difficulties. Eur J Clin Nutr. 2013 Dec;67(S2 Suppl 2):S9-12.

43 Sharp WG, Postorino V, McCracken CE, Berry RC, Criado KK, Burrell TL, et al. Dietary Intake, Nutrient Status, and Growth Parameters in Children with Autism Spectrum Disorder and Severe Food Selectivity: An Electronic Medical Record Review. J Acad Nutr Diet. 2018 Oct;118(10):1943-50.

44 Cooper-Brown L, Copeland S, Dailey S, Downey D, Petersen MC, Stimson C, et al. Feeding and swallowing dysfunction in genetic syndromes. Dev Disabil Res Rev. 2008; 14(2):147-57.
45 Chawner LR, Blundell-Birtill P, Hetherington MM. Interventions for Increasing Acceptance of New Foods Among Children and Adults with Developmental Disorders: A Systematic Review. J Autism Dev Disord. 2019 Sep;49(9): 3504-25.

46 Styne DM, Arslanian SA, Connor EL, Farooqi IS, Murad MH, Silverstein JH, et al. Pediatric Obesity-Assessment, Treatment, and Prevention: An Endocrine Society Clinical Practice Guideline. J Clin Endocrinol Metab. 2017 Mar;102(3):709-57.

47 Clinical and Scientific Advisory Board of the International Prader-Willi Organization. Medical Care for the Adolescent with PraderWilli Syndrome: An Overview of Adolescent Problems for Physicians [cited July 9, 2019]. Available from: https://www.ipwso.org/.

48 Hoelscher DM, Kirk S, Ritchie L, Cunningham-Sabo L; Academy Positions Committee. Position of the Academy of Nutrition and Dietetics: interventions for the prevention and treatment of pediatric overweight and obesity. J Acad Nutr Diet. 2013 Oct;113(10):137594. 